\title{
Automated Smart Utilization of Background Lights and Daylight for Green Building Efficient and Economic Indoor Lighting Intensity Control
}

\author{
Muhammad M. A. S. Mahmoud \\ Process Automation Engineering Department, Baku Higher Oil School, Baku, Azerbaijan \\ Email: mmanar@yahoo.com
}

How to cite this paper: Mahmoud, M.M.A.S. (2021) Automated Smart Utilization of Background Lights and Daylight for Green Building Efficient and Economic Indoor Lighting Intensity Control. Intelligent Control and Automation, 12, 1-15. https://doi.org/10.4236/ica.2021.121001

Received: January 5, 2021

Accepted: February 7, 2021

Published: February 10, 2021

Copyright $\odot 2021$ by author(s) and Scientific Research Publishing Inc. This work is licensed under the Creative Commons Attribution International License (CC BY 4.0).

http://creativecommons.org/licenses/by/4.0/

\begin{abstract}
The ways which are used today in order to light houses, offices, and most of the indoor areas are inefficient as a lot of energy is consumed unnecessarily during the day time. Mainly this problem because the interior lighting design consider the worst case when the light service is at night, which is not always valid. Also in most cases the lighting system design relies on people to control the lights switching on and off. This problem is also one of the design concerns in Green Building. In this paper, a solution to this problem and a method for people's comfort who use the indoor facilities in industrial buildings is presented. In the proposed smart lighting system, lights switch on automatically when there is somebody in the room or in the occupied space and switch off when there is no occupancy. In addition to this known technique, adjustment of the brightness level of the lights will be possible via the personal computer or any other smart device. In this method, for the illumination level in the area, where is needed to be controlled for better energy saving, the light automatically is measured by the sensor and considering the amount of background lights coming from outside, automatically the brightness of lights is controlled to reach the preset level that determined for that room. By the means of this method, it is possible to provide better user comfort, avoid human forcedness to switch the light on and off, and hence effective energy saving. Arduino controller is used to build the controller and to demonstrate the results. Economic analysis was done to calculate the percentage of the energy saving that can be obtained by implementing the proposed smart lighting controller. As an outcome of the economic analysis, energy saving norm for an office with a standard size was calculated.
\end{abstract}

\section{Keywords}

Energy Saving, Lighting Control, Smart Lighting, Green Buildings, Building Automation 


\section{Introduction}

The electrical energy consumed by lighting can be very considerable in places where is huge buildings and multi-occupants, especially in large administrative building. In Today's world, a lot of companies provide methods in order to minimize energy consumption, because energy consumption becomes a significant problem in the developing world. Many pieces of research show that lighting system accounts for approximately $30 \%$ of energy consumption [1] [2]. Especially, departmental stores and big offices located in city territories consume a lot of energy consumption. In offices, lighting systems consume approximately twice more than printers and computers [3]. One of the main causes of this problem is that people leave lights "on" in empty rooms. In almost $23 \%$ of the daytime this event occurs [4]. Another problem that causes to waste of energy is called over-illumination. Over-illumination occurs when lights are brighter than needed to illuminate a room. In addition to this, researches demonstrate that excessive lighting can have negative health effects [4]. This problem, however, still occurs in many buildings everywhere, particularly in offices. And this fact shows that over-illumination occurs during daytime because of external daylight coming into the room. Researches indicate that lights are put off for just one percent during the daytime while the rooms are unoccupied at many intervals [5]. And, in order to overcome these problems, the implementation of an intelligent lighting system can be a great solution.

The direct advantage of an automated lighting system is to reduce energy consumption and maintenance costs. Energy consumption is reduced, because an intelligent lighting system in addition to considering the occupancy status of the room, the external daylight coming into the room is considered as well, hence reduce the amount of power consumed. And, maintenance cost is minimized, since lifetime of the light bulbs is better utilized and this factor extends the span time of light bulbs series. In addition to this, indirect advantages of proposed solution are that it allows the country to export more oil and gas since the consumption of fuel that is needed to generate electricity will be reduced due to the energy savings caused by intelligent lighting system. Also, a reduction in pollution can be considered as another positive advantage for using the smart control for the indoor lighting system, because when less energy is consumed, the amount of carbon dioxide emission released by power generation plants is reduced [6].

It is important to highlight that during the engineering phases of indoor lighting system, because of uncertainty of the amount of daylight and any other background light which penetrates the room, engineers ignore this factor in the design which consequently introduces several drawbacks in the operation and maintenance cost of lighting system. Typical level of illuminance for indoor lighting is given in Table 1 [1].

It is clear from the minimum level of illuminance indicated in Table 1, for each application that the design engineer has to consider the given value as Minimum. 
Table 1. Design average level of illuminance for various places.

\begin{tabular}{ccc}
\hline Facility type & Area or task type & Emin (lux) \\
\hline $\begin{array}{c}\text { general } \\
\text { offices } \\
\text { offices } \\
\text { offices }\end{array}$ & Entrance halls or corridors & 100 \\
Typing, Writing, Reading & 500 \\
restaurant & Technical drawing/Working on computer & $500-750$ \\
schools & Kitchen/Dining room & $200-500$ \\
hospital & Classrooms/Library and Laboratories & $300-500$ \\
& Waiting rooms/Operating theater & $300-500$
\end{tabular}

This make the designer not only ignore any background lighting contribution, but also it considers "Minimum" illumination level that allows the designer to go to higher values to satisfy other design criteria such as symmetrical distribution of lighting inside the room. Also, this "Minimum" value of the illuminance level considered the worst calculation safety-factors that may not be applicable in all cases. Therefore, in general, most of the time in day extra unnecessarily lux level can be obtained inside the room, and hence additional money for operation and maintenance need to be spent.

For better control of the indoor lighting and reduce the operation and maintenance cost of the lighting system, there are many methods to implement intelligent lighting system in order to provide more efficient lighting [7]. First method is to use occupancy sensor in offices, homes etc. In this method, sensor is used to detect occupancy in order to control lights. If there is somebody in the room, lights switch on, otherwise lights switch off automatically. This is a good straight forward and easy method reduce energy consumption but it is not the optimum solution as the method still ignoring the contribution of background lighting entering the room, therefore it cannot be considered as high efficient way to control the indoor lighting intensity for the huge administration buildings that mostly work during the day time.

Second method is to utilize daylight to adjust brightness to a preset level. Energy savings are controlled by using dimming technique in which percentage of illumination of light bulbs change according to daylight coming into the room. Researches show that dimming technique reduces energy consumption up to $30 \%$ compared to non-dimmable light bulbs [8]. Daylight utilization can be accomplished by using light sensors which is used in order to detect level of illuminance inside the room and adjust brightness of the light bulbs on the basis of amount of daylight measured in the room and desired set-point. The energy saving can increase depending on the performance of light sensors used. It is reported by Electric Power Research Institute that daylight utilization can increase energy savings up to approximately $40 \%$ [9]. In addition, researches indicate that energy savings can enhance up to $76 \%$ by taking into account daylight and occupancy status [10].

In this paper, both above mentioned approaches are considered to develop 
intelligent lighting system in order to minimize power consumption and provide sustainable lighting system. Economic analysis is required to be carried out to evaluate this new approach. This integrated approach enables us to adjust brightness of lamps to a preset level, considering daylight coming into the room and also prevent unnecessary lighting in unoccupied places. In the economic analysis, LED lighting type is selected as its power consumption is the lowest among other types of light bulbs, and hence it is expected minimum energy cost saving to be achieved. In case, other type of bulb is used, such as fluorescent or incandescent bulb, the energy saving due to using this intelligent lighting system shall be much higher.

In Section 2, two main types of smart lighting controller schemes are discussed. In Section 3, detailed system-description is illustrated showing block diagram and specifications of the components that are used for the proposed smart lighting system. Section 4 shows the response of the smart lighting controller to three different cases. In Section 5, comprehensive energy saving economic analysis is given for an office with standard size for an administration building.

\section{Typical Lighting Control Scheme}

Energy consumption can be reduced significantly when light bulb's output is controlled automatically. Two methods are commonly used for lighting control. First method uses individual lighting control system in which each light bulb's output is adjusted independently according to light output level of its neighbor bulbs, the second method is networked lighting control system, which is more effective than the first method because all bulbs communicate intelligently with each other in order to achieve the required level for the room light intensity.

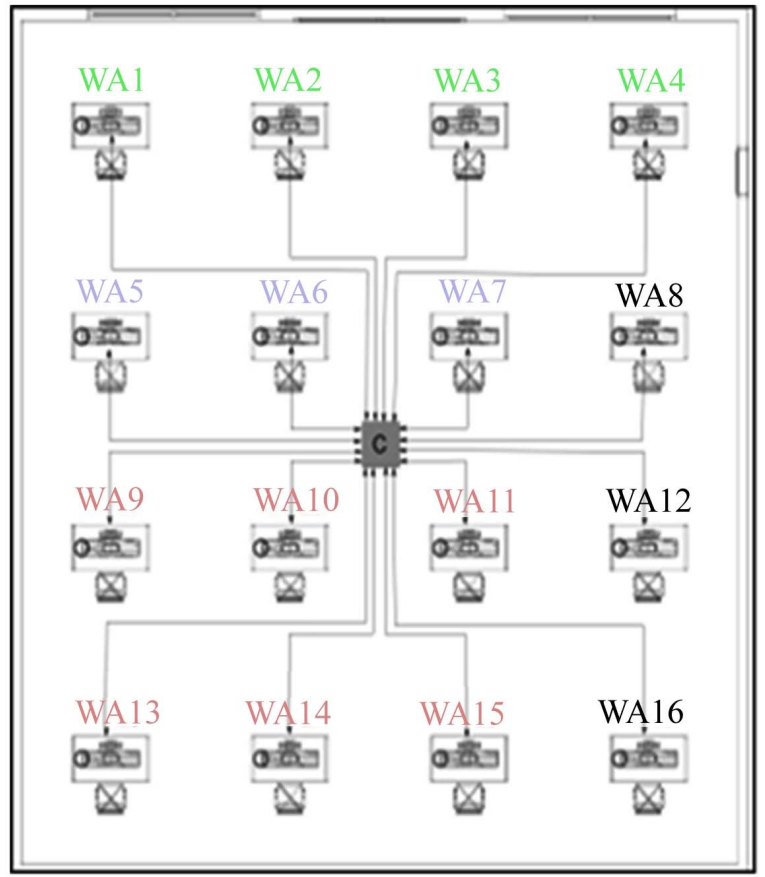

Figure 1. CLC system.

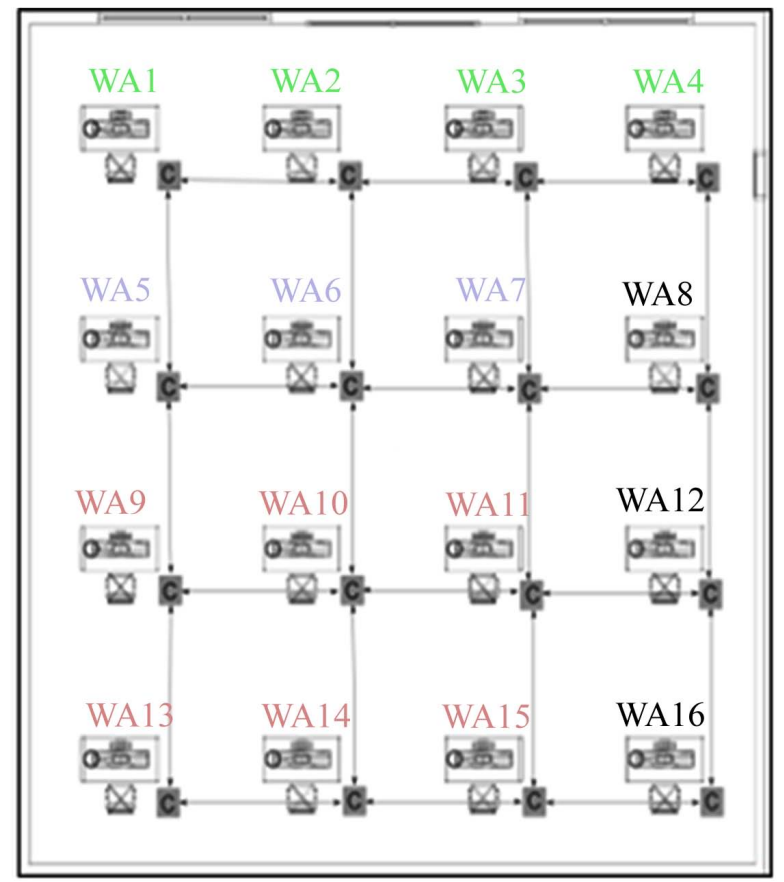

Figure 2. DLC system. 
Networked lighting control system can be classified as DLCS (distributed lighting control system) for first method (Figure 1), or CLCS (centralized lighting control system) for second method (Figure 2). In DLC systems, each light bulb's sensing data is received by the controller, and they can communicate with neighbors in order to adjust their output level according to each other's state. However, in central unit CLCS which receives the status of each node based on information obtained from the sensors, and then performs control actions via actuators. In this system, central unit determines the output level of each light bulb on the basis of data obtained from sensors. In CLCS, many tasks are performed by central unit, such as, acquiring sensors' data from each node, estimating the optimal state where each light bulb will meet light requirements of the room.

\section{System Description for the Proposed Smart Lighting System}

PIR (Passive infrared) sensor is used to sense occupancy in places. PIR sensor detects occupancy at places and send commands to the controller to switch on or off lights. Light intensity sensor(s) is used to give the controller the required data. The control unit sends signal to light dimmer(s) to control the LED light imitation to achieve the preset Lux level required for the room considering daylight. Additional normal florescent light bulb is used to simulate the external daylight.

\subsection{Smart Lighting Systems Methodology}

The term called intelligent luminaire is connected to a smarter level of illumination where devices are capable of creating lighting comfort, energy efficiency, and easy controllability. The concept which is named intelligent lighting system corresponds to a system that communicates and cooperates with many luminaires, creating a node that satisfies user requirements. The key goal of this kind of system is to save energy and, at the same time user comfort by the means of network communication. In Figure 3 the block-diagram of intelligent lighting system is illustrated. It is assumed that lighting system is dimmable (controllable) in order to provide intelligent method to tune the Lux level to the preset value determined by the controller.

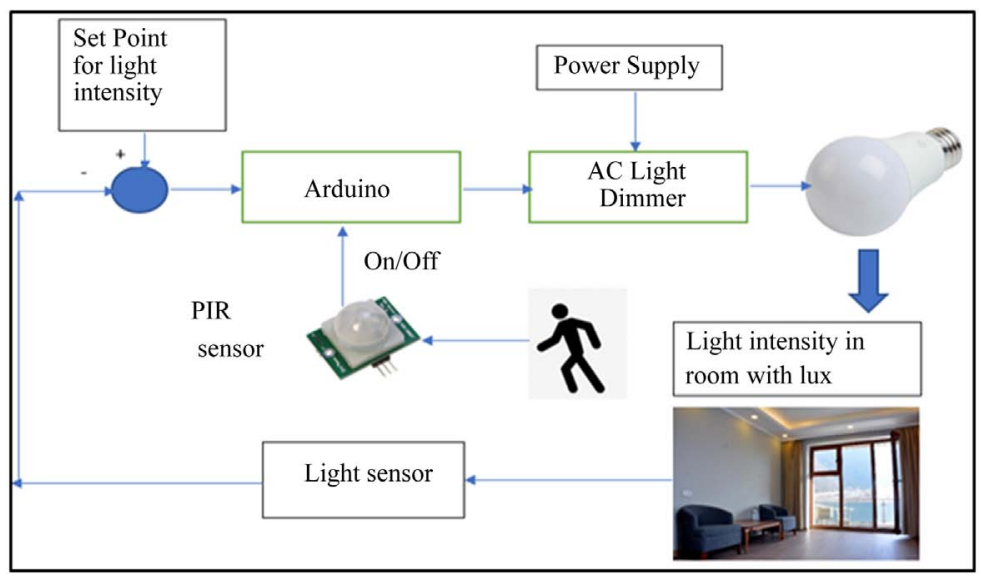

Figure 3. Block diagram of intelligent lighting system. 
Firstly, this system checks for occupancy. If there is no occupancy, Arduino controller sends commands to AC light dimmer (which is controlling the intensity of light bulbs) to switch off lights. If there is somebody in the room, PIR sensor detects occupancy inside the room and activate Arduino controller. Consequently, the controller sends signal to the dimmer(s) to switch on the light and tune the lux of the room to achieve the preset value based on the input provided by the light intensity sensor(s). This control based on the feedback control theory.

\subsection{Smart Lighting System Components}

The smart lighting system contains PIR sensor, BH 1750 light sensor, Arduino Mega, AC light dimmer and LED light bulb(s). To monitor the amount of light (Process Variable-PV) and Set Point (SP), LCD is used.

PIR sensor is one of the simplest and inexpensive type of occupancy sensors and this type of sensor is widely used around the world. It is capable of measuring various air temperatures in the room. When there is somebody in the room, sensor sends a signal to turn on or off lights. When object is moved in the sensor's field of view, infrared lights which is radiating from the objects are measured by PIR sensor. People have a temperature that is higher than perfect zero and thermal energy is emitted from people in the form of radiation. During the day, the wavelength of radiation is approximately $9-10$ micrometers. PIR sensor has capability to detect the wavelength of radiation which only arise when a person comes to sensor's field of view. The radiation emitted by all objects which has temperature above absolute zero cannot be seen by human eye, since it is emitted at infrared wavelengths, however, electronic devices, such as PIR sensor, can detect it. This kind of sensors works totally by sensing the energy emitted by objects. When the amount of heat varies in intensity or position, sensor activates the controller.

PIR sensor which is used in this Intelligent Lighting System possesses pyro-electric sensor module that is designed for the detection of human body. This sensor has sensing range from $3 \mathrm{~m}$ to $4 \mathrm{~m}$, and lens angle is about 140 degrees [11]. One of the advantages of PIR sensor compared with other types of occupancy sensor is that it is not complex, effortless to install, and it has compact size which is $28 * 28 \mathrm{~mm}$. In addition to this, it is highly sensitive, power consumption is very low, and can perform under temperature from -15 to 70 degree. Most significantly, as contrasted with other sensors, it can penetrate walls in which motion can be anticipated and it is cheaper compared with other sensors. However, a constant and slight motion cannot be detected by PIR sensor and this sensor is sensitive to temperature. Another negative side of this sensor is that its field of view is smaller than other type of occupancy sensors. Moreover, this sensor cannot be mounted near the places where temperature changes commonly. But for application of indoor industrial building, this senior is adequate to be used.

BH1750 sensor is used in order to measure light intensity inside the room. This is a digital light sensor, it is also used in mobile phones screen brightness applications. 


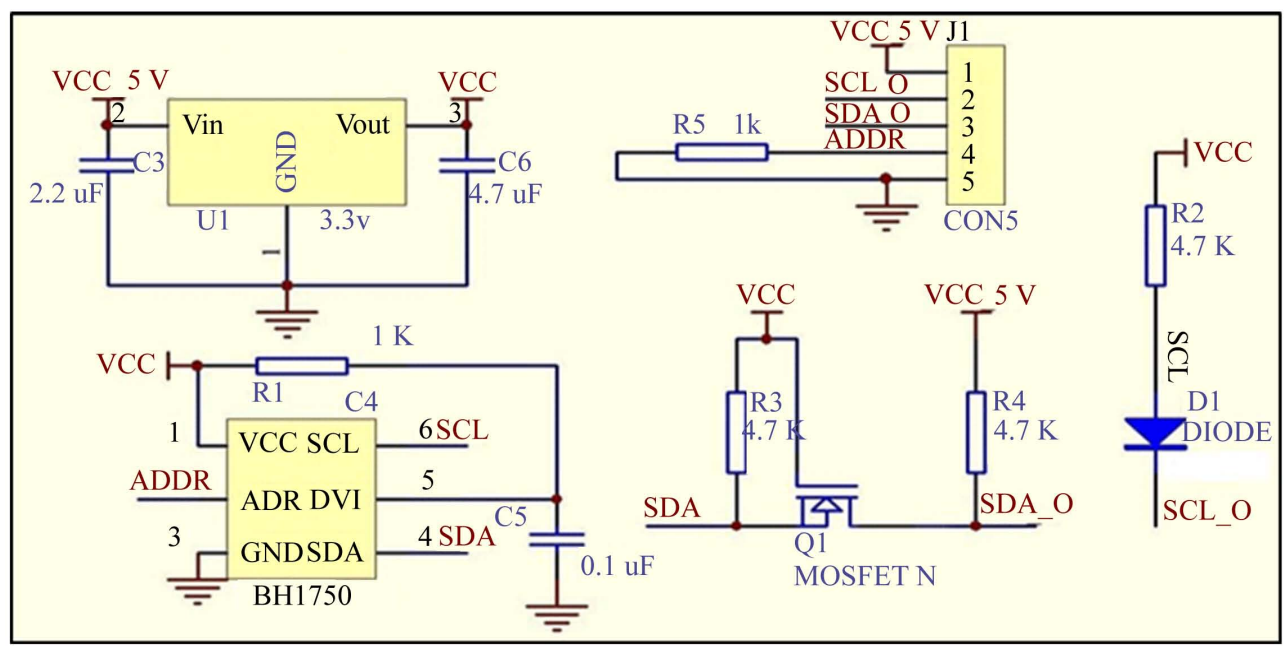

Figure 4. BH 1750 sensor circuit.

This sensor has capability to measure directly lux value and there is no need to convert measured value to lux by interface transducer. This sensor uses I2C protocol to communicate with the controller. This protocol makes it easy to use with microcontroller. SCL and SDA pins that sensor have are required for I2C protocol. One of the advantages is that there is no need for calculation because we can get directly lux value by the means of this sensor. This sensor measures light intensity based on the amount of light which is hitting on it. The voltage between $2.4 \mathrm{~V}$ and $3.6 \mathrm{~V}$ and $0.12 \mathrm{~mA}$ current is needed to operate this sensor. The main component of BH1750 sensor is illustrated in Figure 4.

Arduino Mega is used as a master to control all slaves. It is the brain of this Intelligent Lighting System. It is a type of microcontroller board and uses ATmega 2560 microcontroller. Arduino Mega has 70 I/O pins. Fifty four (54) pins of Arduino Mega are digital I/O pin and 14 of them can be used as PWM pin. Other 16 pins are analog I/O. In addition to this, it consists of 4 UARTs, $16 \mathrm{MHz}$ crystal oscillator, USB connection, power jack, ICSP header, and reset button. Arduino Mega can simply be connected to the computer and programmed. There are many types of shields used for several purposes can be added to the Arduino mega [12].

LED light bulbs are the best choice to use in energy saving lighting systems and they have great advantages over the fluorescent lamps and incandescent light bulbs. In these days, LED bulb technology has developed and this technology offer light bulbs which can be used for many applications. In addition, this type of light bulbs offers dimmable and non-dimmable options and it creates opportunity to be used in intelligent lighting systems. LED bulbs are very durable and no mercury is used in this type of bulbs. Although the initial cost of LED bulbs is higher than other types of bulbs, they are cheaper to use for overall life of the light bulb compared with fluorescent or incandescent light bulbs. For all of these reasons, it can be beneficial to use led bulbs instead of other types of bulbs in the Intelligent Lighting Systems [13]. 
AC Light Dimmer is used to adjust the light intensity by dimming the light bulb [14] coming into the lamp. Nevertheless, when variable resistance is used in order to change the brightness of lamp, resistance converts some part of energy into the heat that is not used. An effective method for dimming is to turn off AC power regularly and provide only some portion of full wave to the light. It could sound strange at first, because it will produce flicker, however it is not visible by human eye, if the periodic light switches and phase of AC power are locked. In order to accomplish the dimming, two circuits are required, zero-crossing detector and pulse-controlled switch, respectively. This is used in order to maintain switching with the power source in phase. And, to deal with $220 \mathrm{~V} \mathrm{AC}$, safety precautions should be implemented. That is why, circuit should be mechanically and electrically isolated from outside by the means of metal box and optoisolators, accordingly. The zero-crossing detector is a full wave rectifier with high power resistors that is used to reduce voltage (Figure 5). And, the pulse-controlled switch contains a Diac or Triac.

Smart System Schematic Diagram: Figure 6 illustrates the schematic diagram for the Smart lighting control system using the component that described above. The system is built and tested and the result of the controller response is given hereinafter.
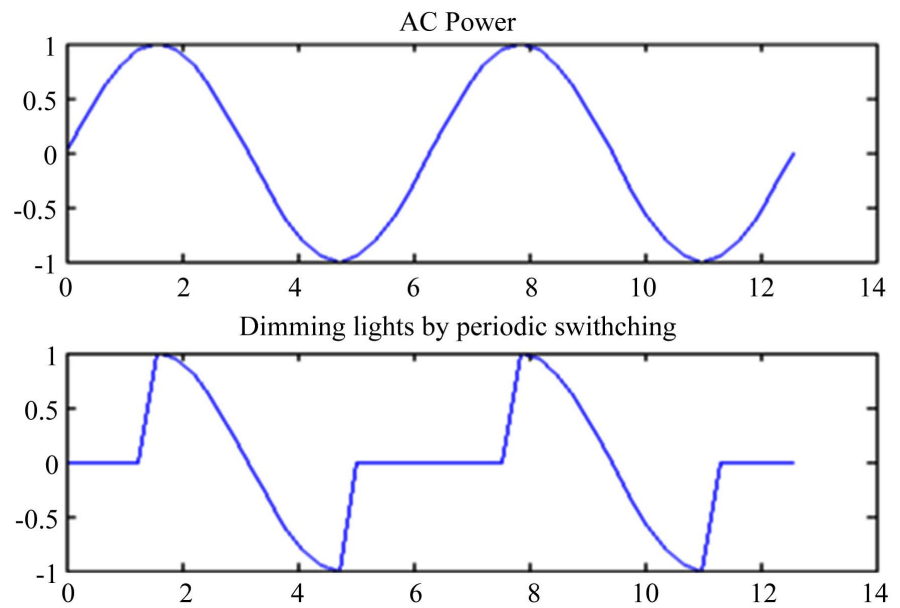

Figure 5. Pulse control using AC light dimmer.

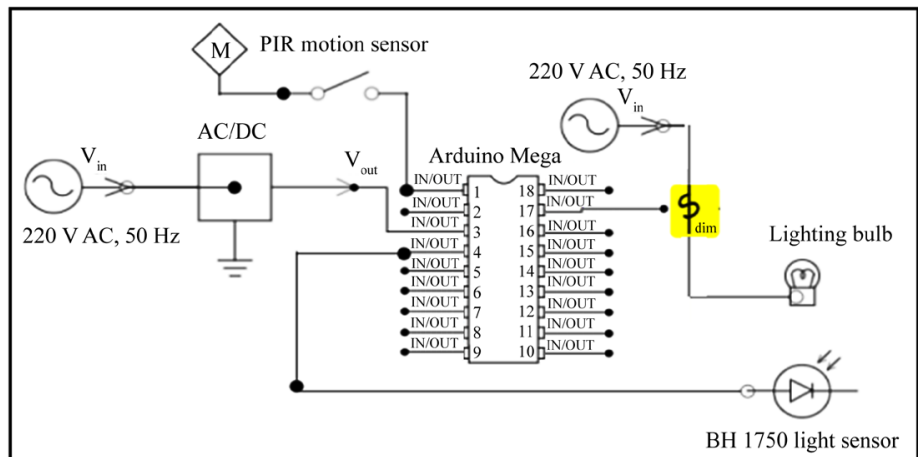

Figure 6. Schematic diagram for the smart lighting control system. 


\section{Smart Lighting System Response}

The response of system will be illustrated for three different preset values and three backgrounds in the room. The response of the system will be represented for occupied conditions. In unoccupied conditions, the intensity of light bulb will be set automatically to zero lux. In Figure 7, the response of the system is illustrated for preset value of 75 lux and external daylight with the amount of 25, 50, and 75 lux, ascending and descending. Another case is considered in Figure 8 represents the response of the system for setpoint of 150 lux and additional daylight with the amount of 50, 100 and 150 lux, ascending and descending. And last test case is considered in Figure 9 shows the response of the system for setpoint 300 lux and external daylight with the amount of 100, 200 and 300 lux, ascending and descending. It is obvious from the results that the dimmer adjusts the light intensity of light bulb to achieve successfully to the preset value, considering the external light coming into the room.

The transient state of the system response is not described in these graphs, only steady state is taken into account, since human's eye doesn't recognize to the fast changes happen in the amount of light. Moreover, in general, the rate of the change in the daylight occurs slowly and gradually, consequently, the response of the controller will change the intensity of the light emitted from the controlled lighting system in small steps which are comfortable for the eye. Hence, the transient state is not concern for the proposed intelligent lighting system.

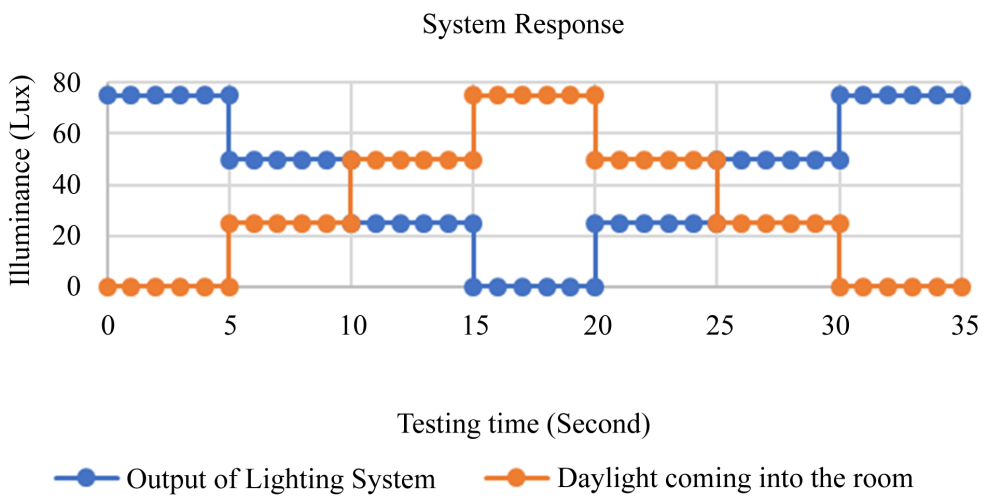

Figure 7. The response of system for 75 lux SP.

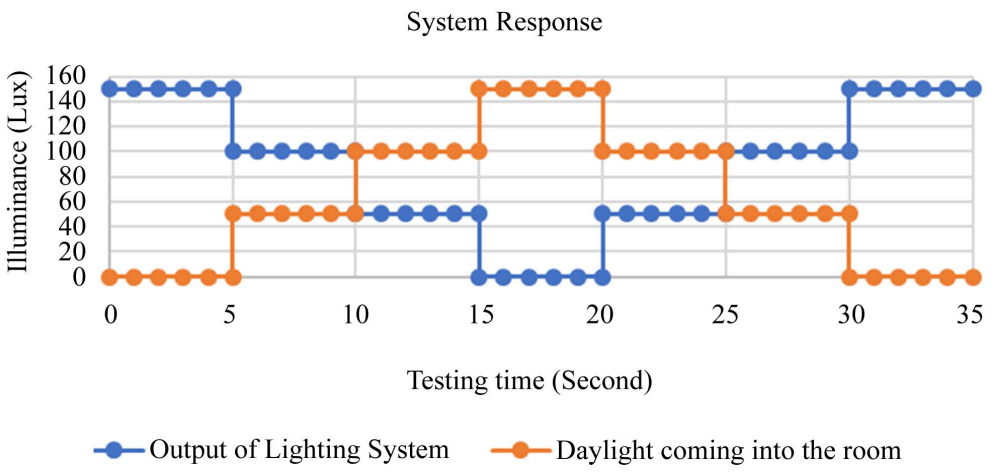

Figure 8. The response of system for 150 lux SP. 
System Response

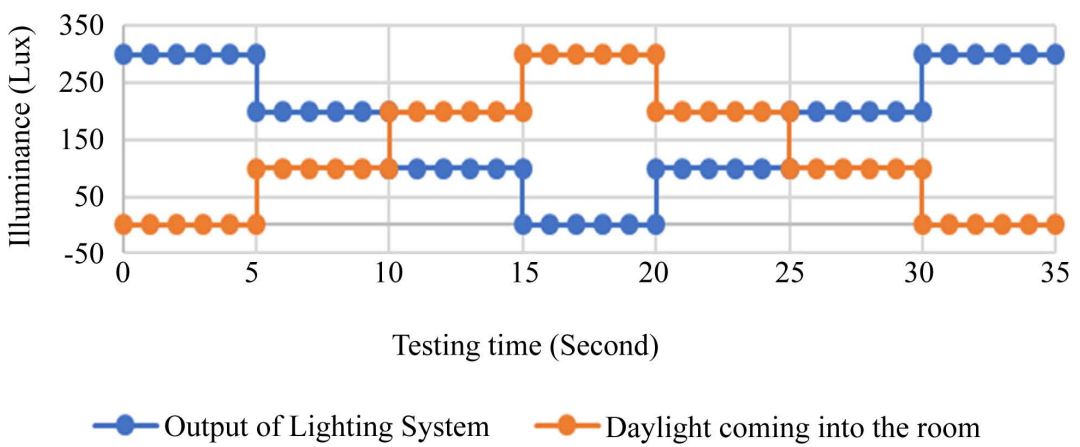

Figure 9. The response of system for 300 lux SP.

\section{Economical Evaluation}

In this section, Techno-Economical evaluation is discussed that includes direct and indirect benefits obtained from using the proposed intelligent lighting system. As mentioned earlier in this Chapter, Direct benefits are categorized in two parts; operational and maintenance cost. However indirect benefit is categorized also into two parts, introducing more oil/gas sale opportunity and reduction of pollution. And, the cost of this intelligent lighting system is negligible compared with other lighting systems.

\subsection{Direct Benefits}

Direct benefits of the proposed Intelligent Lighting System are explained as following:

\subsubsection{Reduction of Operational Cost}

This section determines the energy gains that intelligent lighting system can provide during the day. In order to achieve this, the response of controller is assumed to be maintained during the day. By considering occupancy status and level of illuminance during the day, energy savings which intelligent lighting system can provide may be calculated. A Survey illustrates that workers' illuminance preference is approximately 300 lux, and energy waste is generated by over-illumination and turning on lights in unoccupied places [3].

In Figure 10, Data of illuminance and occupancy status during the day and workers' illuminance preference in typical open-office are illustrated. In this survey, it is assumed that approximately $60 \%$ of daylight is coming into the room. From Figure 10, it can be observed that workers arrive at office at approximately 9:00 AM, occupies the working area and turn on the lighting system, because the level of illuminance is less than 300 lux (However, lighting system plus daylight coming into the room provides more than 300 lux). Thus, at the end of working hour, the lighting system was switched off about at 19:00. Also, from it can also be observed that workers leave working area at different times of the day, but lighting system turned on by causing the energy waste. 


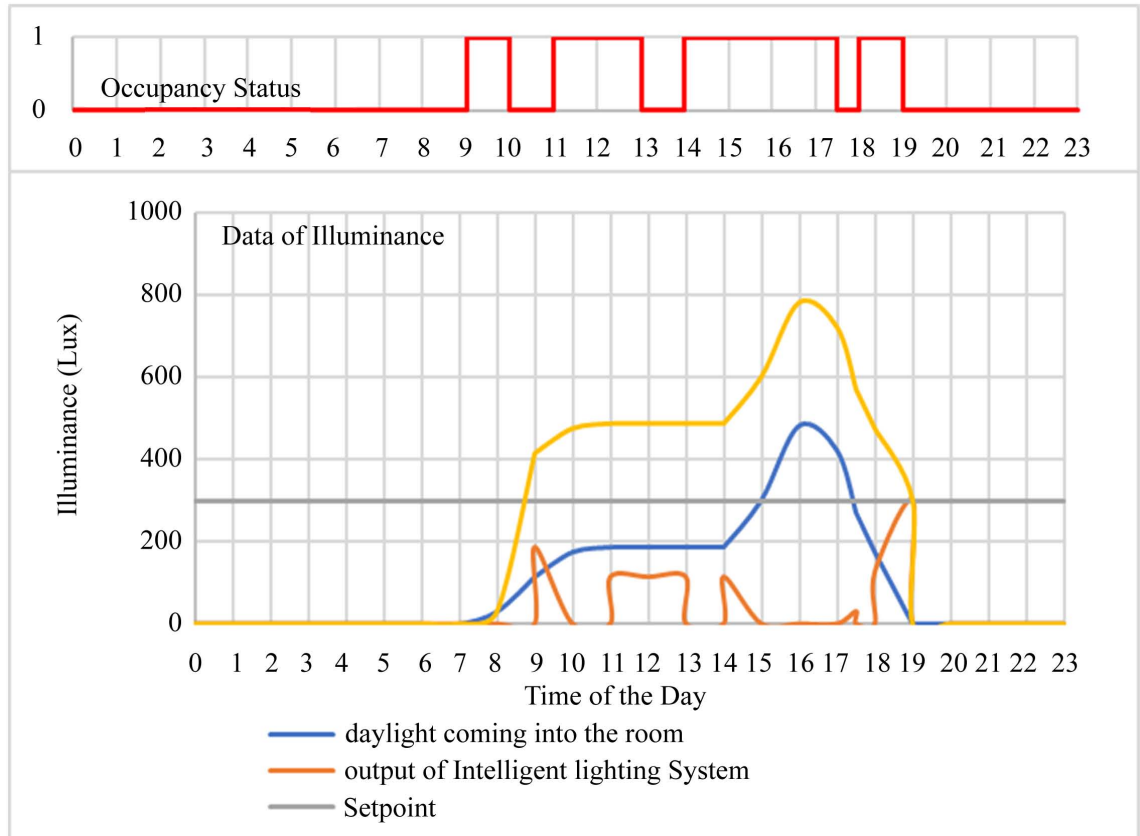

Figure 10. Data of illuminance and occupancy status in typical open-office.

In addition, between 15:00 and 17:00 the illumination which is generated by daylight is sufficient to satisfy the illuminance requirement at the office and lighting system is however switched on by causing over-illumination.

This data represents that thanks to daylight utilization technique, energy can be saved significantly between 9:00 and 19:00 by controlling the amount of light provided by the lighting system. In addition to this, occupancy sensor will contribute us to save energy by switching off lighting system when there is no occupancy in the working area. Finally, the energy savings can be calculated from the Figure 9 by comparing the Areas under the curves. In order to find the energy savings, the area of curves, which are generated by the outputs of intelligent lighting system and Setpoint, should be calculated between 9:00 and 19:00. And, using the following equation, the percentage of energy savings accomplished from intelligent lighting system can be estimated.

A1(Energy for Traditional Lighting System $)=10 * 300=3000$

A2(Energy for Intelgent Lightting System $)=95+240+55+8+150=548$

$$
\text { E.S(Energy saving })=(3000-548) / 3000 * 100 \%=81.7 \%
$$

From the equation above, it is calculated that in typical open-office energy savings can be approximately $81.7 \%$ by implementing proposed intelligent lighting system.

\subsubsection{Reduction of Maintenance Cost}

In Figure 10, it is clearly seen that operation hours of light bulbs reduce from 10 hours to approximately to 5.5 hours. So, implementation of proposed intelligent lighting system contributes also to reduce maintenance cost. The life span of 
light bulbs increases significantly, since lights are switched on at certain times of the day. From Figure 10, percentage of reduction of maintenance cost can be calculated by the means of following equation.

$$
\text { M.C }(\text { maintenance cost })=(10-5.5) / 10 * 100=45 \%
$$

From the equation above, it is calculated that in typical open-office, maintenance cost can be reduced about $45 \%$ by implementing proposed intelligent lighting system.

\subsection{Indirect Benefits}

Explanation of indirect benefits will be given in detail in the following paragraphs.

\subsubsection{Annual Gas Sale Opportunity}

First benefit is that country can export larger amount of gas, since the consumption of gas will be reduced due to the energy savings caused by proposed intelligent lighting system. By using the selling price of \$ 4.618/MMBtu on the basis of US Energy Information Administration Henry Hub/NYMEX, natural gas valued futures prices. Considering $1 \%$ annual escalation factor, equivalent energy rate of $5.6 \mathrm{\$} / \mathrm{kWhr}$ used to measure the energy generated for one year. And, sales opportunity for the natural gas can be estimated annually by the means of Equation (5).

$$
\text { Annual Natural Gas Sale Opportunity }=1.2 \times 0.056 \times \Delta \mathrm{kWhr} \$
$$

The above Equation (5) can be used to calculate the annual gas sale opportunity for any project using this Intelligent Lighting System [15] [16] [17].

\subsubsection{Annual Saving in Pollution}

Second indirect benefit is that pollution caused by power plants can be reduced significantly. When the amount of power consumed is reduced, the amount of toxic fumes released by power plants will be reduced. The majority of power plants burn crude oil, coal, fossil fuel, etc. Hence, this causes the emission of carbon dioxide that accounts for the majority of pollution. Carbon dioxide is released into the air and causes the absorption of sun's warmth and heat in our atmosphere. When power plants burn more fuel in order to generate more energy, extra carbon waste traps cause too much heat. When carbon dioxide emission is reduced, it will cause less pollution. Equation (6) can be used to calculate the Annual Saving in Pollution that can be gained in any project using this Intelligent Lighting System [15] [16] [17].

$$
\text { Annual Saving in Polution }=\frac{0.83 * \Delta \mathrm{kWhr} * 1.2}{1000} \$
$$

\subsection{Energy Saving Norm Calculation}

Consider standard office with dimension $3 \mathrm{~m} \times 4 \mathrm{~m}$. As per Table 1, the design lux level is 500 lux. Using matrix distribution $2 \times 2$ with $60 \mathrm{~cm} \times 60 \mathrm{~cm}$ light fitting, each consists of 4 lighting tube Fluorescent ( $25 \mathrm{~W}$ ) or LED (9 W), the office 
Traditional lighting load shall be $400 \mathrm{~W}$ or $144 \mathrm{~W}$ respectively. For 9 hours working duty, the annual consumption shall be $4730 \mathrm{kWh}$, and $1314 \mathrm{kWh}$.

Applying Equation (3), the office annual energy consumption can be reduced to $865.59 \mathrm{kWh}$ and $240.462 \mathrm{kWh}$ for Fluorescent lighting and LED lighting respectively.

In this paper, Azerbaijan cost of electricity as typical electricity tariff ( 0.10 $\$$ per $\mathrm{KWh}$ ) is considered in the economic analysis. Accordingly, from two values, $865.59 \mathrm{kWh}$ and $240.462 \mathrm{kWh}$, Annual Energy Saving Norm/Office for offices using Fluorescent lighting and LED lighting can be calculated to be 24 \$/office/Year and 86.6 \$/office/Year respectively.

For example, if this technique applied on 100 Administration Building with 50 room each, so the total Annual Saving can be 433,000 \$ and 120,000 \$ for Fluorescent lighting and LED lighting consequently. This example gives good indication how much reasonable saving can be obtained by applying such technique in industrial buildings. This saving is only calculated for energy saving. Still the total saving is higher if maintenance and pollution factors are considered.

\section{Summary and Conclusion}

To conclude this section, it can be highlighted that most places are over illuminated because background light is not considered in the design stage. In addition, light is switched on in unoccupied places which cause waste of energy. Therefore, Intellect Lighting System is very essential to overcome this problem to control indoor lighting intensity taking into account occupancy status and background light coming into the room in order to adjust the level of illuminance in an efficient way. As a result, it is worth to highlight that Intelligent Lighting System uses properly selected LED bulbs not only reduces power consumption but also reduces maintenance cost, pollution caused by power plants and increases the opportunity for gas sales. Finally, a typical Annual Energy Saving Norm (Energy Saving \$/Office) is calculated for both cases, offices using Fluorescent lighting and LED lighting.

\section{Conflicts of Interest}

The author declares no conflicts of interest regarding the publication of this paper.

\section{References}

[1] Marufov, I. and Mahmoud, M.M.A.S. (2020) Intelligent Daylight Utilization for Efficient Indoor Lighting Intensity Control. Graduation Thesis, Baku Higher Oil School, Baku.

[2] Thompson, J. (2013) Are Automated Daylight Control Systems Working as They Should? Victoria University of Wellington, Wellington.

http://hdl.handle.net/10063/2963

[3] Rocha, B.M.R. (2015) Enhanced Networked Luminaire Controller for Sustainable Ambient Illumination. Master Thesis, Instituto Superior Técnico, Lisbon. 
[4] Lombard, L.P., Ortiz, J. and Pout, C. (2008) A Review on Buildings Energy Consumption Information. Energy and Buildings, 40, 394-396.

https://doi.org/10.1016/j.enbuild.2007.03.007

[5] VonNeida, B., Maniccia, D., Tweed, A. and Street, M. (2013) An Analysis of the Energy and Cost Savings Potential of Occupancy Sensors for Commercial Lighting Systems. Journal of the Illuminating Engineering Society, 30, 111-125. https://doi.org/10.1080/00994480.2001.10748357

[6] Mahmoud, M.M.A.S. (2018) Typical Economic Model for Calculating the Saving Norm of Replacement HPS Street Lighting by LED Fixtures in Access Road of Gas Production Company at GCC. IEEE-International Conferences on Electrical and Electronics Engineering, Istanbul, 4-7 May 2018, 189-192. https://doi.org/10.1109/ICEEE2.2018.8391327

[7] Ehrlich, C., Papamichael, K., Lai, J. and Revzan, K. (2001) A Method for Simulating the Performance of Photosensor-Based Lighting Controls. Energy and Buildings, 34, 14-17. https://doi.org/10.1016/S0378-7788(02)00064-6

[8] Edle, J.S., Thakare, A.P. and Agarkar, A.M. (2011) Intelligent Illumination System to Prevail over Possible Diseases due to over- and under-Illumination. International Journal of Enterprise Computing and Business Systems, 1, 40-44

[9] Figueiro, M.G. (2002) Daylight and Productivity: A Possible Link to Circadian Regulation. 5th International LRO Lighting Research Symposium-Light and Human Health, 2002, 185-193. https://ci.nii.ac.jp/naid/10030699713/

[10] Mills, P.R., Tomkins, S.C. and Schlangen, L.J.M. (2007) The Effect of High Correlated Colour Temperature Office Lighting on Employee Wellbeing and Work Performance. Journal of Circadian Rhythms, 5, 45-48. https://doi.org/10.1186/1740-3391-5-2

[11] Islam, N., Rizwan, K.T. and Nifa, S.I. (2013) Smart Departmental Stores. Thesis in Fulfillment of the Requirements for the Bachelor of Science Degree in Electrical \& Electronic Engineering. Brac University, Dhaka.

[12] Arduino. (2018) Getting Started: Foundation-Introduction. https://www.arduino.cc/en/guide/introduction

[13] Cree Edge Ex $^{\text {Tx }}$ (2017) Cree Catalogue. LED Luminaire. Retrieved 9 October 2017. https://www.creelighting-europe.com/wp-content/uploads/2018/10/CatalogoCREE2019_EU_EN-1.pdf

[14] Khan, T., Abbas, H., Ali, S. and Arshad, W. (2015) Design \& Modeling of Self Configuring Automatic Light Control System. Graduation Thesis, University of Engineering and Technology, Lahore.

[15] Mahmoud, M.M.A.S. and Muradkhanli, L. (2020) Economical and Safe Design for Low-Traffic Long Roads Illumination Control System by Using Image Recognition Technique. Journal of Electrical and Electronic Engineering, 8, 117-126. https://doi.org/10.11648/j.jeee.20200805.11

[16] Mahmoud, M.M.A.S. and Muradkhanli, L. (2020) Safer Design and Less Cost Operation for Low-Ttraffic Long-Roads Illumination Using Control System Based on Pattern Recognition Technique. Intelligent Control and Automation, Scientific Research Publishing, 1, 214-225.

[17] Mahmoud, M.M.A.S. (2021) Economic Applications for LED Lights in Industrial Sectors. IntechOpen, 11 January 2021. 


\section{Appendix}

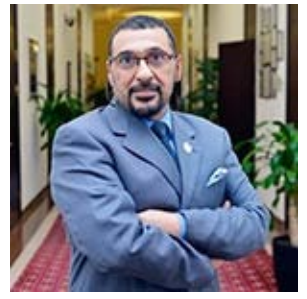

Professor Dr. Muhammad M. A. S. Mahmoud, Egyptian, received the B.S. degree in Electrical Engineering from Cairo University and the M.Sc. degree from Kuwait University. First Ph.D. degree from Transilvania University of Brasov, Romania in IT and Computer. Second $\mathrm{PhD}$ Degree in Electrical Power system and Machine, Cairo Univ. Egypt. He occupies a position of Professor in Process Automation Engineering Department, Baku Higher Oil School, Azerbaijan. His current research interests in Fuzzy and Artificial Neural Network Techniques application include power delivery, protection reliability, control, safety, building automation, smart city, and energy management. Prof. Dr. Muhammad is IEEE Senior Member (SM) since 2001 and TFS-IEEE Reviewer 2016. 